\title{
Concurrent radiochemotherapy in advanced hypopharyngeal cancer
}

\author{
Valentina Krstevska' ${ }^{1}$ Igor Stojkovski*t1 and Dusko Lukarskit2
}

\begin{abstract}
Background: Concurrent platinum-based radiochemotherapy has been recommended as a standard of care in patients with locally advanced squamous cell head and neck carcinomas. Unfortunately, there is a lack of level one evidence on best treatment approach for advanced hypopharyngeal cancer. This report aims to summarize the results of our study on concurrent radiochemotherapy in patients with advanced hypopharyngeal cancer.

Methods: A retrospective analysis of 41 patients with stage III-IV hypopharyngeal cancer was performed. All patients were treated with three dimensional conformal radiotherapy and received 70 Gy in 35 fractions (2 Gy per fraction, 5 fractions per week). In dependence of the period when radiotherapy was realized, two different treatment techniques were used. Concurrent chemotherapy consisted of cisplatin $30 \mathrm{mg} / \mathrm{m}^{2}$ given on a weekly basis.

Results: The median age was 52 years (range 29-70). Stage IV disease was recognized in $73.2 \%$ of the patients. Complete response rates at the primary site and at the metastatic neck lymph nodes were $68.3 \%$ and $36.6 \%$, respectively. A complete composite response was present in 27 patients (65.9\%). Median follow-up was 13 months (range 7-36). Distant metastases as initial failure occurred in 7 patients (46.7\%). The 2-year local relapse-free survival and regional relapse-free survival rates were $55.2 \%$ and $75.8 \%$, respectively. The 2 -year locoregional relapse-free survival rate was $51.3 \%$. The 2-year disease-free survival and overall survival rates were $29.3 \%$ and $32.8 \%$, respectively. Confluent mucositis was developed in $46.3 \%$ of patients. Leucopenia grade 1 was the most frequent hematological toxicity. The median weight loss at the end of treatment was $12 \%$ (range 5-21). The worst grade of late toxicity was most commonly pronounced in the skin and in the subcutaneous tissue.

Conclusions: Based on unsatisfactory results in our study we suggest that the use of sequential radiochemotherapy or chemotherapy given concomitantly with altered fractionation radiotherapy with the implementation of intensitymodulated radiotherapy as radiotherapy technique could represent treatment approaches able to improve outcome in patients with advanced hypopharyngeal cancer.
\end{abstract}

\section{Background}

Hypopharyngeal cancer is a rare disease representing about $0.5 \%$ of all human malignancies with an incidence of less than 1 per 100000 population and constituting only $3-5 \%$ of all head and neck cancers $[1,3]$. Hypopharyngeal cancers are often at an advanced stage at diagnosis and are associated with a poor prognosis [4,6]. The reasons for the unfavourable prognosis of hypopharyngeal cancers are the strong tendency for extensive submucosal spread, the early occurrence of regional lymphatic

\footnotetext{
* Correspondence: istojkovski@gmail.com

1 Department of Head and Neck Cancer, University Clinic of Radiotherapy and Oncology, Skopje, Macedonia

+ Contributed equally

Full list of author information is available at the end of the article
}

involvement, and the relatively high rate of distant spread $[7,8]$.

In the 1970s and 1980s, surgery, followed by postoperative radiotherapy was the standard form of therapy for advanced stage disease $[9,10]$. This radical approach of treatment, lead to the loss of natural speech function and impairment of swallowing ability with a consequent negative impact on the quality of life, and low cure rates, reported 5-year survival between $20.0 \%$ and $50.0 \%$ $[1,2,7,11,12]$.

The necessity for improvement of survival rates and preserving organ function resulted in introduction of chemotherapy as a third treatment modality for patients with advanced hypoharyngeal cancer. The combined modality treatment was subject of analysis in two ran- 
domized trials. In the study of Beauvillain et al. [13] comparing chemotherapy plus radiotherapy with chemotherapy plus surgery plus radiotherapy, the outcome was better in the surgical arm. In the randomized trial conducted by the European Organization for Research and Treatment of Cancer (EORTC) Head and Neck Cancer Cooperative group, comparing chemotherapy plus radiotherapy with surgery plus radiotherapy, surgical and non-surgical groups had similar 5-year survival [14]. Both studies did not succeed to give evidence to support radical surgery for curative treatment for advanced hypoharynegal cancer. Also, the EORTC 24891 trial [15] demonstrating that laryngeal preservation by induction chemotherapy followed by definitive radiotherapy was a safe treatment alternative for patients with T2T4 tumours, worked as a good basis for further investigations of non-surgical management of hypopharyngeal cancers [16].

Concurrent radiochemotherapy (CRCT) as definitive treatment for advanced head and neck including cancers arising from the hypopharynx has been studied in the past 15 years $[17,23]$.

However, due to the low incidence, hypopharyngeal cancers grouped with other head and neck cancers usually represented only smaller subgroups with details of their treatment being rarely specifically reported $[8,16]$. The rarity of this disease, and the time needed for data collection could be accepted as an explanation for the absence of multicenter randomized clinical trials undertaken to evaluate the role of CRCT in the treatment of advanced hypopharyngeal cancer. Despite the fact that concurrent platinum-based radiochemotherapy was adopted as a standard of care in patients with locally advanced HNSCC [24], there is no level one evidence on best treatment [16], or agreement on treatment for advanced hypoharyngeal cancer [25].

In order to evaluate the results of non-surgical combined treatment approach we retrospectively analyzed patients with advanced hypopharyngeal cancer treated with chemotherapy consisting of cisplatin given on a weekly basis administered concurrently with externalbeam radiotherapy performed using three dimensional conformal technique.

\section{Methods}

Forty-one consecutive patients with newly diagnosed advanced stage III-IV squamous cell carcinoma of the hypopharynx treated with definitive CRCT, from January 2006 to October 2009 at the University Clinic of Radiotherapy and Oncology in Skopje were analyzed. Pre-treatment evaluations included history, physical examination, panendoscopy and biopsy, computed tomography (CT) and/or magnetic resonance imaging (MRI) of the hypopharyngeal and cervical region, chest $\mathrm{x}$-ray, liver ultra- sound and routine laboratory studies. Patients were staged according to the 2002 criteria of the American Joint Committee on Cancer [26]. Written informed consent was obtained from the patients for including in the study. A copy of the consent is available for review by the Editor-in-Chief of this journal.

\section{Radiotherapy}

The patients were immobilized in supine position with a thermoplastic head and neck mask. They were treated by photons with beam qualities of $6 \mathrm{MV}$ and $15 \mathrm{MV}$ and electrons with energies 9-16 MeV. For the treatment planning, we used the Eclipse Version 7.3.10, a commercial 3D treatment planning system manufactured by Varian Medical Systems. The CT scanning was made for each patient in the treatment position with slice thickness of $0.5 \mathrm{~cm}$.

The gross tumour volume of the primary tumour (GTVt70) and the metastatic lymph nodes (GTVn70) were defined as any visible tumour and the gross nodal disease revealed on imaging studies and/or physical examination. Neck lymph nodes were considered metastatic when their smallest axis diameter was greater then $1.0 \mathrm{~cm}$. The clinical target volume (CTVt50) encompassed the GTVt70 plus a margin of $1.0-2.0 \mathrm{~cm}$ for the potential microscopic extension of the disease. In patients with negative neck lymph nodes the CTVn50 included the nodal regions in the neck at levels II-IV. In patients with clinically involved neck lymph nodes, CTVn50 included GTVn70 with a margin of $0.5-1.0 \mathrm{~cm}$ and also encompassed retropharyngeal lymph nodes and nodal regions at levels I-V. Level VI was included in CTVn50 only in cases when primary tumour invaded oesophagus. CTV50 was created by integration of CTVt50 and CTVn50. The planning target volumes were PTV50 and PTV70. The PTV50 provided a margin of 0.5 $\mathrm{cm}$ around CTV50. If there were no positive lymph nodes in the neck, the PTV70 encompassed the GTVt70 plus a $0.5 \mathrm{~cm}$ margin. In patients with nodal disease, the GTV70 was union of GTVt70 and GTVn70, and by adding a margin of $0.5 \mathrm{~cm}$ around it, we obtained PTV70.

The patients were treated by two different treatment techniques.

The first treatment technique used from January 2005 until January 2008, consisted of three stages. In the first stage we used semi-fields, where the upper neck was irradiated by two opposing lateral semi-fields, and the lower neck was irradiated by anterior and posterior semi-fields. For the posterior semi-field we used $15 \mathrm{MV}$ photons, and for the other fields, $6 \mathrm{MV}$ photons. This stage consisted of 23 fractions, 2 Gy each. In the second stage, comprising of 2 fractions, 2 Gy each, the lateral fields were reduced from the dorsal side in order to exclude the spinal cord from the fields. The dose to the shielded dorsal part of the 
PTV50 was delivered by two lateral electron fields, which were matched to the photon fields. In the third stage of the treatment, depending on the position and the volume of the PTV70, we used arrangements with 2 to 4 photon fields with beam quality $6 \mathrm{MV}$ in lateral or oblique directions with occasional use of electron fields, delivering the remaining $20 \mathrm{~Gy}$ in 10 fractions. In this stage the spinal cord was completely out of field.

The second technique, started from February 2008, which we have named "oblique photon fields" technique, consisted of two stages. The idea was to eliminate the use of electron fields, because of the inconveniences that occur when matching photon and electron fields (the cold spots at the surface or the hot spots at greater depth). In the first stage we delivered 50 Gy in 25 fractions by 4 oblique isocentric photon fields of beam quality $6 \mathrm{MV}$. Two of the fields, the anterior ones, were positioned at gantry angles $300^{\circ}$ and $60^{\circ}$ and covered the whole PTV50. The posterior oblique fields were at gantry angles between $210^{\circ}$ and $220^{\circ}$ from the right side of the patient, and between $135^{\circ}$ and $145^{\circ}$ from the left side. The spinal cord was shielded in these fields, so they covered only part of the PTV50. The weight of the posterior fields was approximately 4 times smaller than the weight of the anterior ones. The second stage was identical to the third stage of the first technique.

\section{Chemotherapy}

Chemotherapy consisted of cisplatin $30 \mathrm{mg} / \mathrm{m}^{2}$ along with standard hydration and antiemetic prophylaxis given to the patients concomitantly with radiation on a weekly basis. Patients commenced chemotherapy on the same day as commencing radiotherapy. The full blood count and biochemistry were checked weekly before chemotherapy. The criteria of skipping or stopping chemotherapy were leucopoenia or experienced severe mucositis.

\section{Response assessment}

Response evaluation was performed three months after completion of radiochemotherapy by physical examination, computed tomography CT and/or MRI, and endoscopy under general anaesthesia. For the primary tumour, a complete response was defined as complete disappearance of clinical and radiological evidence of disease with a complete recovery of larynx mobility. Partial response was defined as a regression of a $50 \%$ or more of the tumour volume and at least a partial recovery of the larynx mobility. A complete nodal response was defined as a complete disappearance of the enlarged lymph nodes. A partial response was defined as a $50 \%$ or more decrease of the sum of product of perpendicular diameters of all measurable nodes on imaging. No response (NR) was defined as stable or progressive disease. Complete com- posite response was considered when both complete primary and nodal response were achieved.

\section{Follow-up}

According to the follow-up policy of our clinic, patients were examined weekly during radiochemotherapy to assess treatment-induced toxicity. After the completion of treatment, all patients were followed up every month over the first year, every other month in the second year, and at 3- to 6-month intervals thereafter. A physical examination and fiberoptic endoscopy were performed during each follow-up examination. Baseline $\mathrm{CT}$ and/or MRI of the neck were done every 6 months over the first 2 years. Additional investigations were performed whenever necessary. Biopsy was performed if there was suspicion of residual or recurrent disease.

\section{Treatment toxicity assessment}

Acute reactions induced by radiotherapy were assessed according to the Acute Radiation Morbidity Scoring Criteria of the Radiation Therapy Oncology Group (RTOG) [27] and scored on a weekly basis during the course of treatment and monthly during the first 3 months after the end of treatment. Chemotherapy-related toxicities were assessed according to the World Health Organization (WHO) criteria [28] and were also recorded on a weekly basis during radiochemotherapy. Late radiotherapyrelated toxicities were evaluated according to the scales of the European Organization for Research and Treatment of Cancer/Radiation Therapy Oncology Group (EORTC/ RTOG) [27] and were recorded starting at 6 months after treatment completion.

\section{Statistical analysis}

The end points examined were local relapse-free survival (LRFS), regional relapse-free survival (RRFS), locoregional relapse-free survival (LRRFS), distant metastasesfree survival (DMFS), disease-free survival (DFS), and OS. LRFS was calculated from the first day of treatment until the day when a recurrence at the primary site was first reported, or until the day of the last follow-up. Patients who did not achieve complete primary response were assigned a LRFS of 0 months. RRFS was calculated from the first day of treatment until the day of first occurrence of nodal recurrence, or until the day of the last follow-up. Patients without complete nodal response were assigned a RRFS of 0 months. LRRFS was also evaluated and calculated from the first day of treatment until the day of first occurrence of primary and/or neck relapse, or until the day of the last follow-up. Patients who did not achieve complete composite response were assigned a LRRFS of 0 months. DMFS was measured from the start of treatment to the date of occurrence of clinically detected DM or to the date of the last follow-up. DFS was calculated from the first day of treatment to the date 
when a relapse was first recorded or, in the case of persistent disease, to the date of first follow-up. The end point of DFS was the occurrence of local, regional or distant relapse. Patients without evidence of disease were censored at the date of last follow-up. OS was calculated from the start of treatment until death, or to the most recent follow-up date. The endpoint for OS was death from all causes. LRFS, RRFS, LRFS, DMFS, DFS and OS curves were calculated using the Kaplan-Meier method [29].

\section{Results}

\section{Patients characteristics}

The patient characteristics are described in Table 1 . The median age was 52 years (range, 29-70), with a male predominance $(80.5 \%)$. The most common primary subsite was pyriform sinus, present in $78.0 \%$ of patients. Locally advanced primary tumour (T4) was recognized in 25 patients (61.0\%). More than one-half of the patients were diagnosed with metastatic neck nodes. Clinically negative neck (N0) was present in 17 patients (41.5\%). In the whole number of patients more than two-thirds were seen with stage IV disease (73.2\%). Moderate histological differentiation was present in 17 patients $(41.5 \%)$. The most frequent symptom at diagnosis was painful swallowing present in $56.1 \%$ of patients.

\section{Compliance of treatment}

All treated patients received the full planned dose of radiotherapy (70 Gy). In 36 patients $(87.8 \%)$, the overall treatment time (OTT) for radiotherapy completion was $\leq$ 7 weeks. Photon-electron treatment was realized in 13 patients (31.7\%). The rest 28 patients (68.3\%) were irradiated using the technique with oblique photon fields. Twenty-two patients completed all seven cycles of concurrent chemotherapy. Six cycles of cisplatin was given in 16 patients, while 3 patients had less than six cycles of cisplatin with patients' refusal being the only cause for concurrent chemotherapy cessation. The mean total dose of cisplatin given was $192 \mathrm{mg} / \mathrm{m}^{2} \pm 23.2 \mathrm{SD}$.

\section{Response to treatment}

A complete response at the primary site occurred in 28 patients (68.3\%). In patients with positive neck the achieved complete response rate was $36.6 \%$. A complete composite response was present in 27 patients (65.9\%). A partial composite response was registered in 14 patients (34.1\%). Of those, only one patient had a complete response of the primary tumor and a partial response of the nodal disease. In all other patients, there was a partial response at the primary site and at the neck region.

\section{Patterns of failure}

Median patient follow-up at the commencement of the analysis was 13 months (range 7-36). Local recurrence was developed in 3 patients, 1 patient developed regional recurrence, and 4 patients developed both. Distant metastases were the predominant initial failure occurred in 7 patients and accounting for $46.7 \%$ of the cases who manifested a relapse of the disease. Distant metastases were also developed in 3 patients who had not achieved complete composite response following treatment. Hence, the overall incidence of distant metastases was $24.4 \%(10 / 41)$. Not one patient had an identification of distant metastatic disease preceded by the occurrence of local and/or regional recurrence. The most frequent site of distant metastases $(80.0 \%)$ was the lungs. The median time to development of local recurrence was 12 months (range 4-19). Regional recurrence developed as a single event occurred at 7 months after beginning of treatment. The median time to occurrence of locoregional recurrence and distant metastases was 10.5 months (range 919 ) and 9.5 months (range 4-21), respectively.

\section{Survival}

At the time of analysis, 19 patients were alive. Among those, 1 patient had recurrence in the neck nodes, 1 patient had recurrence of the primary tumour, 2 patients had recurrence of the primary and of the nodal disease, 4 patients had distant metastases, and 11 patients were alive free of disease. During the follow-up period, due to tumor progression, a tracheotomy had been performed in 8 patients, 3 patients required a placement of a feeding tube, and in other 3 patients a gastrostomy had been performed. Death was disease-related in vast majority of patients (21/22). Three patients had died of local or locoregional recurrence, 1 patient had unknown cause of death, 12 patients had died of the progression of their persistent disease, 3 patients had died of distant metastases, and 3 patients had died due to both persistent disease and distant metastases.

The 2-year LRFS and RRFS survival rates were 55.2\% and $75.8 \%$, respectively (Figure 1 ). The median duration of LRFS was 10 months (range 0-36) and the median duration of RRFS was 12 months (range 0-36). The LRRFS at 2 years was $51.3 \%$ (Figure 1). The median duration of LRRFS was 10 months (range 0-36). The DMFS at 2 years was $64.7 \%$ (Figure 2). The median duration of DMFS was 12 months (range 4-36). The 2-year DFS and OS survival rates were $29.3 \%$ and $32.8 \%$, respectively (Figure 3). The median duration of DFS was 9 months (range 3-36) and the median duration of OS was 14 months (range 7-36). 
Table 1: Patients characteristics $(n=41)$.

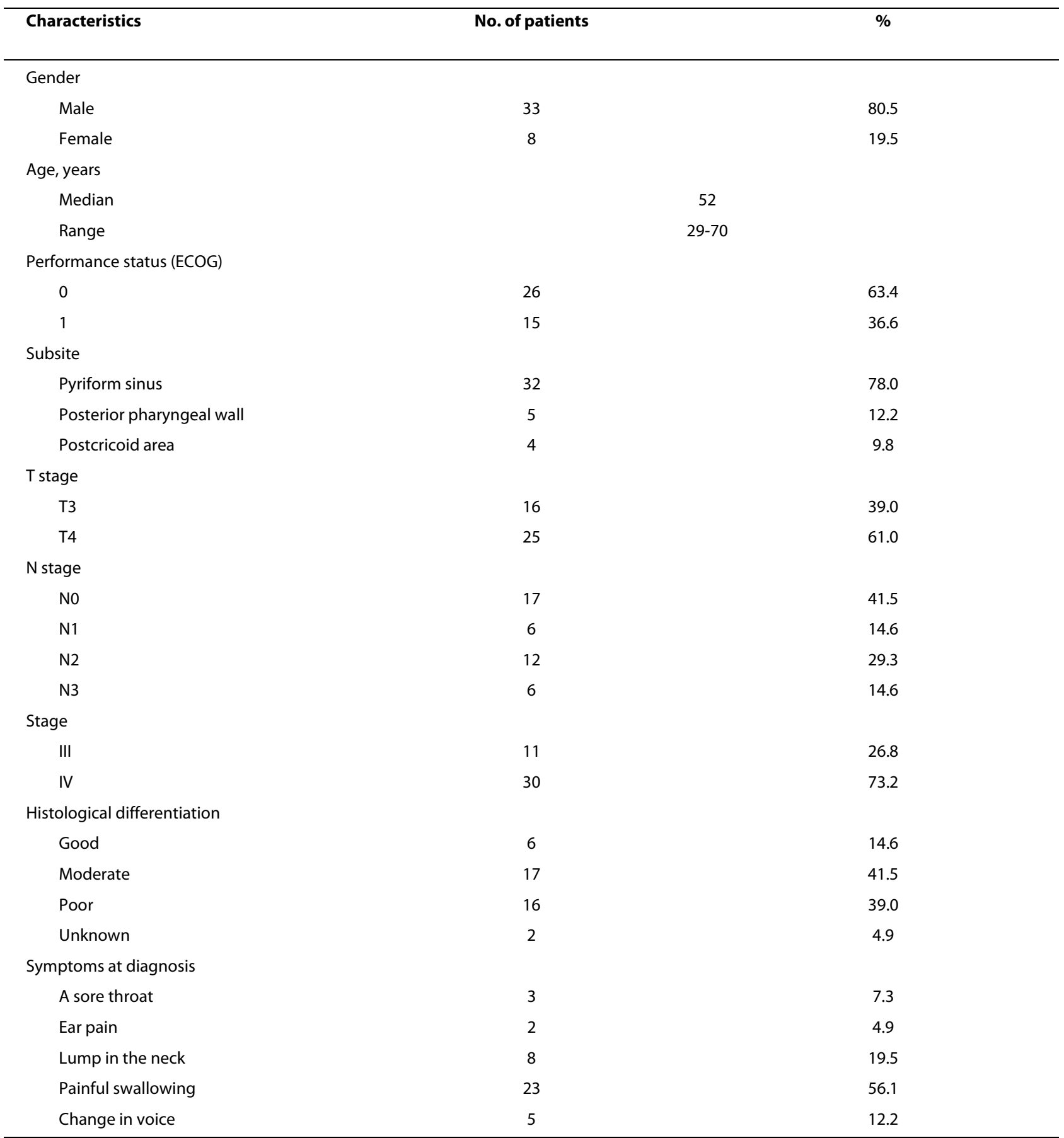

ECOG, Eastern Cooperative Oncology Group.

\section{Toxicity}

The acute toxic effects of treatment are illustrated in Table 2. Grade 2 skin reaction (deep hyperpigmentation and dry desquamation) was developed in $75.6 \%$ of patients. Grade 3 skin reaction (moist desquamation) was manifested in only $4.9 \%$ of patients. Grade 2 mucous membrane reaction (patchy mucositis) was developed in
$48.8 \%$ of patients. Similar proportion $(46.3 \%)$ of patients developed confluent mucositis (grade 3 mucous membrane reaction). The most common grade of acute reaction in the pharynx was grade 2 , experienced in $73.2 \%$ of patients. The most frequent haematological toxicity was leucopenia grade 1 , present in $70.7 \%$ of patients. The median weight loss at the end of radiochemotherapy was 


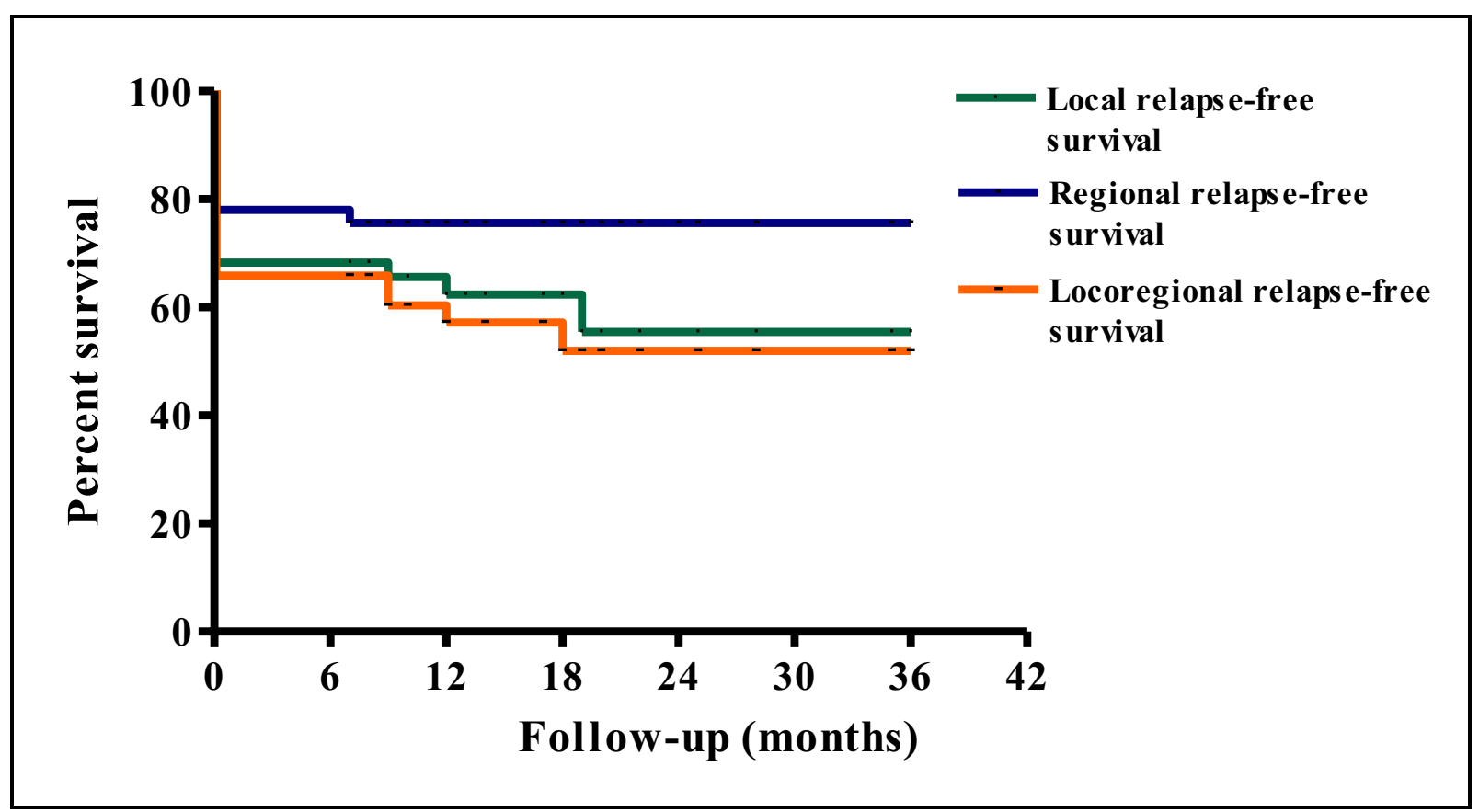

Figure 1 Kaplan-Meier curves of local relapse-free survival, regional relapse-free survival and locoregional relapse-free survival.

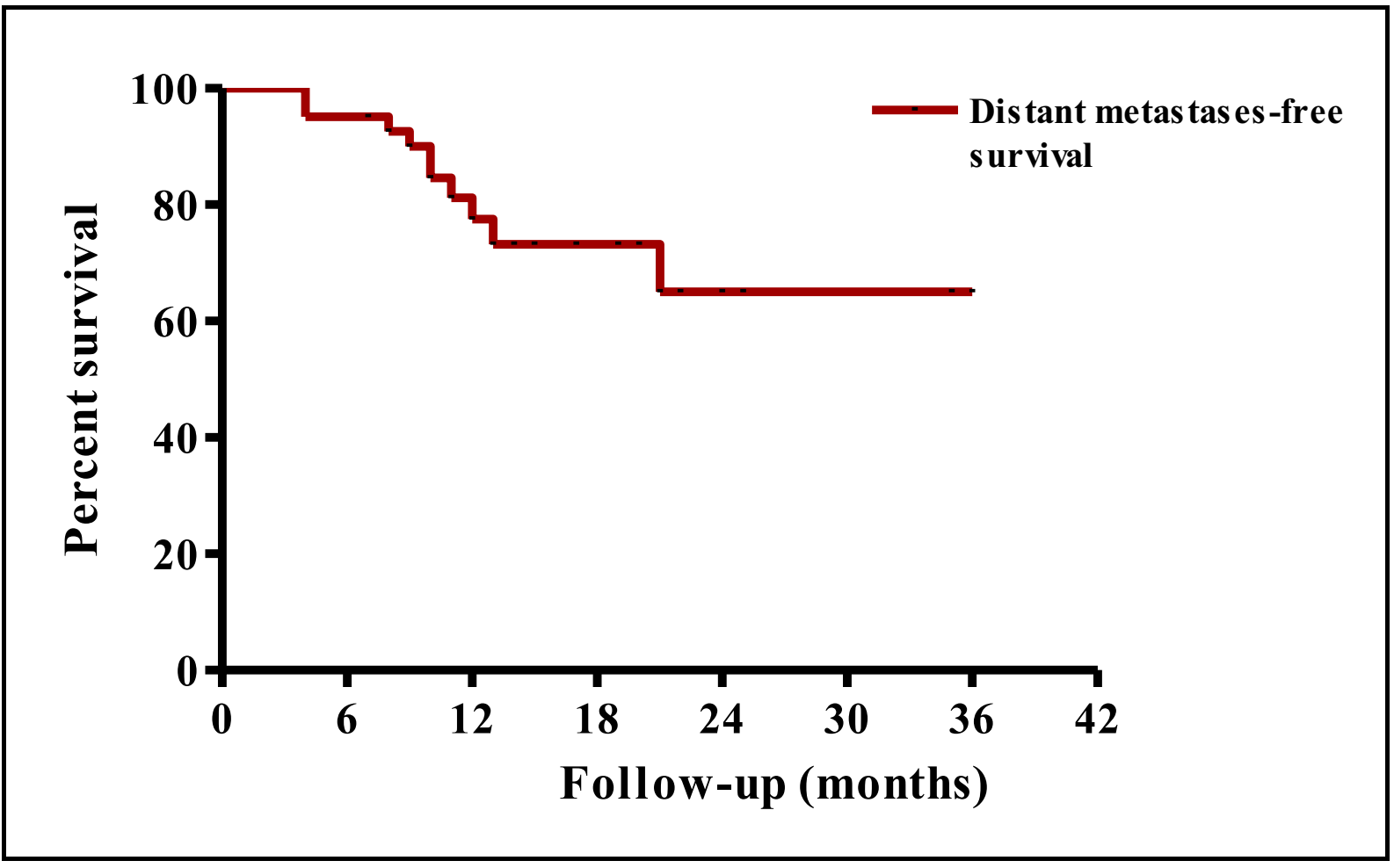

Figure 2 Kaplan-Meier curve of distant metastases-free survival. 


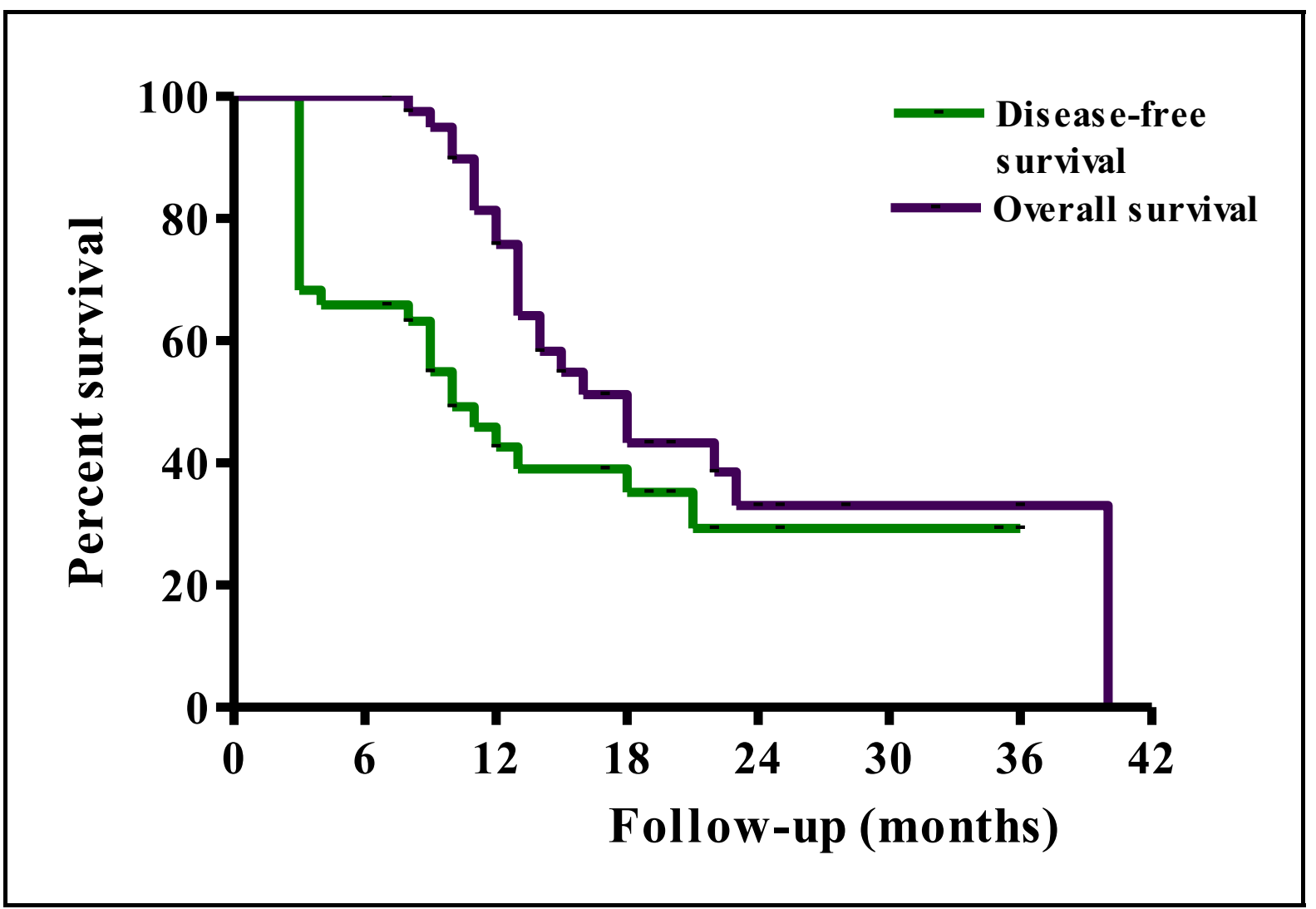

Figure 3 Kaplan-Meier curves of disease-free survival and overall survival

12.0\% (range 5-21). Late normal tissue reactions are listed in Table 3. The worst grade of late toxicity (grade 2) was most commonly found in the skin (34.1\% of patients) and in the subcutaneous tissue (65.9\% of patients).

\section{Discussion}

Hypopharyngeal cancer is a head and neck neoplasm with one of the most unfavourable prognosis. Although there is no level one evidence on best treatment for advanced hypopharyngeal cancer [16], considering the fact that vast majority of patients presenting with advanced stage disease are inoperable, unfit for operation, or refuse surgery, we found the use of chemotherapy and radiotherapy administered concomitantly as a rational treatment option for this patient category.

The achieved rate of complete composite response in our study was $65.7 \%$. This result is comparable with the results observed in other studies investigating the effectiveness of combined radiotherapy and chemotherapy for advanced hypopharyngeal carcinoma. Yoon et al. [30] reported a complete response rate of $82.0 \%$ in the group of 28 patients treated with induction chemotherapy followed by CRCT. In the retrospective study comparing the results of treatment of locally advanced hypopharyngeal cancer with two different protocols, Hung et al. [4] found the response rate of $77.0 \%$ in 38 patients treated with definitive CRCT followed by adjuvant chemotherapy.

The results of our study demonstrated that grade 3 acute response of the mucous membrane was present in almost one half of the patients (48.8\%). This corresponds with the findings of other authors $[4,31]$. The rate of grade 2 weight loss registered in our study was $53.6 \%$, but we did not observe increased rates of chemotherapyrelated haematological toxic effects. Although the incidence of development of confluent mucositis was expected to be increased with CRCT and was thought to affect treatment course, there was no treatment interruption occurring in the event of swallowing disturbance in our study. Also, none of the patients had to discontinue treatment as a consequence of haematological toxicity. Using three dimensional conformal radiotherapy and concomitant weekly cisplatin we succeeded to deliver the prescribed dose of 70 Gy in all the patients, and there were only 3 patients receiving less than six cycles of concurrent chemotherapy. 
Table 2: Acute toxicity induced by concurrent chemoradiotherapy.

\begin{tabular}{|c|c|c|c|c|}
\hline \multirow[b]{2}{*}{ Toxicity } & \multicolumn{4}{|c|}{ Grade of reaction (\% of 41 patients) } \\
\hline & 0 & 1 & 2 & 3 \\
\hline \multicolumn{5}{|c|}{ Acute normal tissue reactions according to RTOG criteria } \\
\hline \multicolumn{5}{|l|}{ Organ/Tissue } \\
\hline Skin & 0 & 19.5 & 75.6 & 4.9 \\
\hline Mucous membrane & 0 & 4.9 & 48.8 & 46.3 \\
\hline Salivary gland & 0 & 34.1 & 61.0 & 4.9 \\
\hline Pharynx & 0 & 21.9 & 73.2 & 4.9 \\
\hline Larynx & 24.4 & 36.6 & 39.0 & 0 \\
\hline \multicolumn{5}{|c|}{ Acute toxicity according to WHO criteria } \\
\hline \multicolumn{5}{|l|}{ Nonhematological } \\
\hline Nausea & 46.3 & 51.2 & 2.4 & 0 \\
\hline Vomiting & 63.4 & 34.1 & 2.4 & 0 \\
\hline Weight loss & 0 & 43.9 & 53.6 & 2.4 \\
\hline \multicolumn{5}{|l|}{ Hematological } \\
\hline Leucopenia & 19.5 & 70.7 & 9.8 & 0 \\
\hline Anemia & 36.6 & 56.1 & 7.3 & 0 \\
\hline Thrombocytopenia & 51.2 & 48.8 & 0 & 0 \\
\hline
\end{tabular}

RTOG, Radiation Therapy Oncology Group; WHO, World Health Organization.

* Because of rounding, not all percentages total 100.

In our study locoregional recurrence occurred in 8 patients. Distant metastases as an initial failure occurred in 7 patients. The overall incidence of distant metastases was $24.4 \%$. Similar findings were obtained by other authors. In the study of Hung et al. [4], distant metastases also occurred in $24.0 \%$ of patients treated with CRCT. In the retrospective analysis of Elias et al. [32] on treatment results of carcinoma of the pyriform sinus, $32.0 \%$ of patient population developed distant metastases. The fre- quency of DM of $46.7 \%$ as first site of failure in our study was ten fold higher compared to the results reported by Johansen et al. [2]. Although it is generally considered that locoregional control of head and neck cancer represents an important factor for development of distant metastases, we did not observe any distant metastases development preceded by occurrence of locoregional recurrence. This data led us to assume that there had

Table 3: Late normal tissue reactions.

Grade of reaction (\% of 41 patients)

\begin{tabular}{lccc} 
Organ/Tissue & $\mathbf{0}$ & $\mathbf{1}$ & $\mathbf{2}$ \\
\hline Skin & 2.4 & 63.4 & 34.1 \\
Subcutaneous tissue & 0 & 34.1 & 65.9 \\
Mucous membrane & 0 & 87.8 & 12.2 \\
Salivary gland & 9.8 & 75.6 & 14.6 \\
\hline
\end{tabular}

* Because of rounding, not all percentages total 100. 
been a high probability for the presence of occult distant metastases at the time of initial patients screening.

The LRRFS at 2 years revealed in our study was 51.3\%, a result that differs from the 2-year locoregional progression-free survival rate for patients with hypopharyngeal cancer of $73.0 \%$ in the study of Lee et al. [31]. In the study of Yoon et al. [30], the 3-year locoregional control for the group treated with CRCT was 52.0\%. Johansen et al. [2] in their study of treatment results in 138 patients with hypopharyngeal carcinoma reported low rates of locoregional control at 5 years $(25.0 \%)$. The 2-year DMFS rate in our study was $64.7 \%$. In contrast, Lee et al. [31] reported rate of 2-year freedom from distant metastasis of $92.0 \%$. In the study of Kim et al. [33] on treatment results in advanced hypopharyngeal carcinoma according to treatment modalities, the 5-year DMFS rate in the group treated with induction chemotherapy and radiotherapy was $82.4 \%$. The rate of 2-year DFS in our study is similar to the 3-year DFS rate of $28.8 \%$ for stage IV hypoharyngeal cancer in the study of Gupta et al. [34]. In the study of Hung et al. [4], there was also a very low rate of 3-year DFS (21.0\%). The OS rate at 2 years in our study was $32.8 \%$ and was lower than the reported 2-year OS rate of $53.0 \%$ in the study of Lee et al. [31]. A higher rate of OS was also reported by Yoon et al. [30] and by Hung et al. [4] (3-year OS rate of $54.0 \%$ and $43.0 \%$, respectively).

Considering the rates of LRRFS, DMFS, DFS, and OS in our study, and comparing them with the rates observed in other clinical studies, we must conclude that irrespectively to the combined treatment modality used (CRCT, induction chemotherapy with radiotherapy, or CRCT followed by adjuvant chemotherapy), the results were far from being satisfactory. At this point, the necessity of locoregional control improvement and decrease of distant metastases as critical factors for increase in DFS and OS survival must be taken in consideration. The implementation of intensity-modulated radiotherapy (IMRT) as sophisticated radiotherapy technique combined with concomitant chemotherapy, the use of altered fractionation regimens, the use of intensified concurrent radiochemotherapy, the adoption of sequential therapy, and the administration of targeted therapy concurrently with conventional or altered fractionation, could be considered as combinations of treatment factors able to contribute to the ultimate outcome of patients with advanced hypoharyngeal cancer.

The possibility for higher dose delivery in the tumor while sparing critical structures by using IMRT are reasonably expected to enable improvement in locoregional control in advanced hypopharyngeal cancer.

The improvement of locoregional control in advanced head and neck cancer has been achieved by the use of altered fractionated radiotherapy [35,38]. In the metaanalysis of 15 trials examining the role of altered fraction- ation radiotherapy in head and neck cancer, Bourhis et al. [39] reported that altered fractionation improves 5-year local control by $6.4 \%$ and 5 -year OS by $3.4 \%$ compared with conventionally fractionated radiotherapy with significantly higher benefit seen with hyperfractionated radiotherapy. The comparison of conventionally fractionated radiotherapy with altered fractionation radiotherapy in the German meta-analysis of 32 randomized trials on patients with squamous cell carcinoma of the head and neck (oral cavity, oropharynx, hypopharynx, and larynx) also showed that hyperfractionation led to a significant improvement of OS if radiotherapy was used as single treatment modality [40].

Regarding the confirmed role of CRCT as a recommendable treatment option in advanced head and neck cancer $[41,42]$ and considering the confirmed advantage of altered fractionation over conventionally fractionated radiotherapy, the intensified CRCT (altered fractionation and concurrent chemotherapy) should be also considered as another attempt to further improve both locoregional control and OS. In the prospective randomized clinical study in advanced oropharyngeal, oral cavity and hypopharyngeal cancer conducted by Budach et al. [43], altered fractionation radiotherapy with CRCT was found superior to altered fractionation radiotherapy alone. The analysis on altered fractionation radiotherapy in combination with concurrent chemotherapy in the German meta-analysis resulted in an OS benefit of $12.0 \%$ compared to altered fractionation radiotherapy alone, that was similar to the survival benefit achieved with conventionally fractionated radiotherapy with concurrent chemotherapy, compared with conventionally fractionated radiotherapy alone [40]. These results suggested that the use of concurrent chemotherapy enabled a significant improvement in OS, regardless of the fractionation regimen employed.

The development of distant metastases during followup period represents a serious problem reflecting negatively on DFS and OS in patients with advanced hypopharyngeal cancer. The adoption of CRCT as a standard of care for patients with locally advanced HNSCC is associated with improved locoregional control and OS compared to radiotherapy alone [39,40], and its efficacy to decrease the rate of distant metastatic disease has been also confirmed in phase III trials that have tested this treatment option $[23,44,45]$.

Targeted therapy in head and neck cancer is closely connected to the use of cetuximab, an anti-Epidermal Growth Factor Receptor (EGFR) antibody therapy, confirmed to be effective in combination with radiotherapy in previously untreated patients in a single controlled clinical trial $[46,47]$. The recently started phase III trial (RTOG 0522) exploring cisplatin-based CRCT with or 
without cetuximab is expected to clarify the role of cetuximab in integrated radiochemotherapy association [48].

\section{Conclusions}

Taking into account the unsatisfactory results achieved using CRCT in our study, we strongly advocate an emerged change of therapeutic approach in patients with advanced hypopharyngeal cancer.

Concerning the radiotherapy technique in the treatment of hypopharyngeal cancer, we recommend the adoption of IMRT in the routine clinical practice because of its more conformal dose distribution with steep gradients between PTV and critical structures.

We also consider that hyperfractionation, in the presence of sufficient radiotherapy resources, could be implemented as treatment modality with beneficial impact on OS in patients with advanced hypopharyngeal cancer.

Accepting platinum-based CRCT, in the absence of conclusive arguments supporting exact schedule of cisplatin administration, we advocate the use of weekly cisplatin considering it as the simplest solution that provides radiosensitizing effect to a larger proportion of the radiotherapy dose and leads to less chemotherapy induced toxicity.

\section{Competing interests}

The authors declare that they have no competing interests.

\section{Authors' contributions}

VK and IS have made substantial contributions to design of the study and collected the data. VK performed much of the work and drafted the manuscript. $\mathrm{DL}$ has been involved in drafting the manuscript in the section of radiotherapy techniques. VK and IS interpreted the data. VK performed the statistical analysis. All authors read and approved the final manuscript.

\section{Author Details}

1Department of Head and Neck Cancer, University Clinic of Radiotherapy and Oncology, Skopje, Macedonia and ${ }^{2}$ Department of Radiation Physics, University Clinic of Radiotherapy and Oncology, Skopje, Macedonia

Received: 30 March 2010 Accepted: 18 May 2010

Published: 18 May 2010

\section{References}

1. Hoffman HT, Karnell LH, Funk GF, Robinson RA, Menck HR: The National Cancer Data Base report on cancer of the head and neck. Arch Otolaryngol Head Neck Surg 1998, 124:951-962.

2. Johansen LV, Grau C, Overgaard J: Hypopharyngeal squamous cell carcinoma: treatment results in 138 consecutively admitted patients. Acta Oncol 2000, 39:529-536

3. Cooper JS, Porter K, Mallin K, Hoffman HT, Weber RS, Ang KK, Gay EG, Langer CJ: National Cancer Database report on cancer of the head and neck: 10-Year update. Head Neck 2009, 31:748-758.

4. Hung S-K, Chen H-L, Hsieh C-H, Hsu W-L, Chang K-H, Liu D-W, Chen Y-J, Lee M-S: Treatment of advanced hypopharyngeal cancer-comparison of two modalities. Tzu Chi Med J 2006, 18:15-21.

5. Ho CM, Ham KH, Wei WI, Yuen PW, Lam LK: Squamous cell carcinoma of the hypopharynx--analysis of treatment results. Head Neck 1993, 16:405-412

6. Pingree TF, Davis RK, Reichman O, Derrick LM: Treatment of hypopharyngeal carcinoma: a 10-year review of 1,362 cases. Laryngoscope 1987, 97:901-904.
7. Lajtmam Z, Manestar D: A comparison of surgery and radiotherapy in the management of advanced pyriform fossa carcinoma. Clin Otolaryngol 2001, 26:59-61.

8. Tai S-K, Yang M-H, Wang L-W, Tsai T-L, Chu P-Y, Wang Y-F, Huan J-L, Chang S-Y: Chemoradiotherapy laryngeal preservation for advanced hypopharyngeal cancer. Jpn J Clin Oncol 2008, 38:521-527.

9. Arriagada R, Eschwege F, Cachin Y, Richard JM: The value of combining radiotherapy with surgery in the treatment of hypopharyngeal and laryngeal cancers. Cancer 1983, 51:1819-1825.

10. Mirimanoff RO, Wang CC, Doppke KP: Combined surgery and postoperative radiation therapy for advanced laryngeal and hypopharyngeal carcinomas. Int JRadiat Oncol Biol Phys 1985, 11:499-504.

11. Sewnaik A, Hoorweg JJ, Knegt PP, Wieringa MH, Beek JMH van der, Kerrebijn JDF: Treatment of hypopharyngeal carcinoma: analysis of nationwide study in the Netherlands over a 10-year period. Clin Otolaryngol 2005, 30:52-57.

12. Kim WT, Ki YK, Nam JH, Kim DW, Lee BJ, Wang SG, Kyuon BH: The results of postoperative radiotherapy for hypopharyngeal carcinoma. J Kor Soc Thera Radiol Onco 2004, 22:254-64.

13. Beauvillain $C$, Mahe $M$, Bourdin $S$, Peuvrel $P$, Bergerot $P$, Rivière A, Vignoud J, Deraucourt D, Wesoluch M: Final results of a randomized trial comparing chemotherapy plus radiotherapy with chemotherapy plus surgery plus radiotherapy in locally advanced resectable hypopharyngeal carcinomas. Laryngoscope 1997, 107:648-653.

14. Lefebvre JL, Rolland F, Tesselaar M, Bardet E, Leemans CR, Geoffrois L, Hupperets P, Barzan L, de Raucourt D, Chevalier D, Licitra L, Lunghi F, Stupp R, Lacombe D, Bogaerts J, Horiot JC, Bernier J, Vermorken JB: Phase 3 randomized trial on larynx preservation comparing sequential vs alternating chemotherapy and radiotherapy. J Nat/ Cancer Inst 2009, 101:142-152.

15. Lefebvre J-L, Chevalier D, Luboinski B, Kirkpatrick A, Collette L, Sahmoud T: Larynx preservation in pyriform sinus cancer: preliminary results of a European Organization for Research and Treatment of Cancer phase III trial. J Natl Cancer Inst 1996, 88:890-899.

16. Robson A: Evidence-based management of hypopharyngeal cancer. Clin Otolaryngol 2002, 27:413-420.

17. Forastiere AA, Goepfert H, Maor M, Pajak TF, Weber R, Morrison W, Glisson B, Trotti A, Ridge JA, Chao C, Peters G, Lee DJ, Leaf A, Ensley J, Cooper J: Concurrent chemotherapy and radiotherapy for organ preservation in advanced laryngeal cancer. N Engl J Med 2003, 349:2091-2098.

18. Adelstein DJ, Saxton JP, Rybicki LA, Esclamado RM, Wood BG, Strome M, Lavertu P, Lorenz RR, Carroll MA: Multiagent concurrent chemoradiotherapy for locoregionally advanced squamous cell head and neck cancer: mature results from a single institution. J Clin Oncol 2006, 24:1064-1071.

19. Urba SG, Moon J, Giri PGS, Adelstein DJ, Hanna E, Yoo GH, LeBlanc M Ensley JF, Schuller DE: Organ preservation for advanced resectable cancer of the base of tongue and hypopharynx: a southwest oncology group trial. J Clin Oncol 2005, 23:88-95.

20. Wendt TG, Grabenbauer GG, Rodel CM, Thiel HJ, Aydin H, Rohloff R, Wustrow TP, Iro H, Popella C, Schalhorn A: Simultaneous radiochemotherapy versus radiotherapy alone in advanced head and neck cancer: a randomized multicenter study. J Clin Oncol 1998, 16:1318-1324.

21. Brizel DM, Albers ME, Fisher SR, Scher RL, Richtsmeier WJ, Hars V, George SL, Huang AT, Prosnitz LR: Hyperfractionated irradiation with or without concurrent chemotherapy for locally advanced head and neck cancer. N Engl J Med 1998, 338:1798-1804.

22. Vokes EE, Stenson K, Rosen FR, Kies MS, Rademaker AW, Witt ME, Brockstein BE, List MA, Fung BB, Portugal L, Mittal BB, Pelzer H, Weichselbaum RR, Haraf DJ: Weekly carboplatin and paclitaxel followed by concomitant paclitaxel, fluorouracil, and hydroxyurea chemoradiotherapy: curative and organ-preserving therapy for advanced head and neck cancer. J Clin Oncol 2003, 21:320-326.

23. Jeremic B, Shibamoto Y, Milicic B, Nikolic N, Dagovic A, Aleksandrovic J, Vaskovic Z, Tadic L: Hyperfractionated radiation therapy with or without concurrent low-dose daily cisplatin in locally advanced squamous cell carcinoma of the head and neck: a prospective randomized trial. J Clin Oncol 2000, 18:1458-1464.

24. Corvo R: Evidence-based radiation oncology in head and neck squamous cell carcinoma. Radiother Oncol 2007, 85:156-170. 
25. Hall SF, Groome PA, Irish J, O'Sullivan B: Radiotherapy or Surgery for Head and Neck Squamous Cell Cancer. Establishing the Baseline for Hypopharyngeal Carcinoma? Cancer 2009, 115:5711-5722.

26. Greene FL, Page DL, Fleming ID, Fritz A, Balch CM, Haller DG, Morrow M: AJCC Cancer Staging Manual. Volume 6. New York: Springer-Verlag; 2002:31-46.

27. Cox JD, Stetz J, Pajak TF: Toxicity criteria of the Radiation Therapy Oncology Group (RTOG) and the European Organization for Research and Treatment of Cancer (EORTC). Int J Radiat Oncol Biol Phys 1995, 31:1341-1346.

28. Miller AB, Hoogstraten B, Staquet M, Winkler A: Reporting results of cancer treatment. Cancer 1981, 47:207-214.

29. Kaplan EL, Meier P: Concurrent chemoradiotherapy with cisplatin and fluorouracil for locally advanced hypopharyngeal carcinoma. J Am Stat Assoc 1958, 53:457-81.

30. Yoon MS, Chung W-K, Ahn S-J, Nam T-K, Nah B-S, Song J-Y, Lim SC, Lee JK: Concurrent chemoradiotherapy with cisplatin and fluorouracil for locally advanced hypopharyngeal carcinoma. Acta Oto-Laryngol 2008, 128:590-596.

31. Lee NY, O'Meara W, Chan K, Della-Bianca C, Mechalakos JG, Zhung J, Wolden SL, Narayana A, Kraus D, Shah JP, Pfister DG: Concurrent chemotherapy and intensity-modulated radiotherapy for locoregionally advanced laryngeal and hypopharyngeal cancers. Int $\mathrm{J}$ Radiat Oncol Biol Phys 2007, 69:459-468.

32. Elias MM, Hilgers FJM, Keus RB, Gregor RT, Hart AAM, Balm AJM: Carcinoma of the pyriform sinus: a retrospective analysis of treatment results over a 20-year period. Clin Otolaryngol 1995, 20:249-253.

33. Kim S, Wu H-G, Heo D-S, Kim KH, Sung M-W, Park C II: Advanced hypopharyngeal carcinoma treatment results according to treatment modalities. Head Neck 2001, 23:713-717.

34. Gupta T, Chopra S, Agarwal JP, Laskar S-G, D'Cruz AK, Shrivastava SK, Dinshaw KA: Squamous cell carcinoma of the hypopharynx: Singleinstitution outcome analysis of a large cohort of patients treated with primary non-surgical approaches. Acta Oncol 2009, 48:541-548.

35. Cummings B, Keane T, Pintilie M, Warde P, Waldron J, Payne D, Liu F, Bissett R, MsLean M, Gullane P: Five year results of a randomized trial comparing hyperfractionated to conventional radiotherapy over four weeks in locally advanced head and neck cancer. Radiother Oncol 2007, 85:7-16.

36. Fu KK, Pajak TF, Trotti A, Jones CU, Spencer SA, Phillips TL, Garden AS, Ridge JA, Cooper JS, Ang KK: A Radiation Therapy Oncology Group (RTOG) phase III randomized study to compare hyperfractionation and two variants of accelerated fractionation to standard fractionation radiotherapy for head and neck squamous cell carcinoma: first report of RTOG 9003. Int J Radiat Oncol Biol Phys 2000, 48:7-16

37. Overgaard J, Hansen H, Specht L, Overgaard M, Grau C, Andersen E, Bentzen J, Bastholt L, Hansen O, Johansen J: Five compared with six fractions per week of conventional radiotherapy of squamous-cell carcinoma of head and neck: DAHANCA 6\&7 randomized controlled trial. Lancet 2003, 363:933-940.

38. Skladowski K, Maciejewski J, Golen M, Pilecki B, Przeorek W, Tarnawski R: Randomized clinical trial of 7-day continuous accelerated irradiation (CAIR) of head and neck cancer: report on 3-year tumor control and normal tissue toxicity. Radiother Oncol 2000, 55:93-102.

39. Bourhis J, Overgaard J, Audry H, Ang KK, Saunders M, Bernier J, Horiot J-C, Le Maitre A, Pajak TF, Poulsen MG, O'Sullivan B, Dobrowsky W, Hliniak A, Skladowski K, Hay JH, Pinto LHJ, Fallai C, Fu KK, Sylvester R, Pignon J-P: Hyperfractionated or accelerated radiotherapy in head and neck cancer: a meta-analysis. Lancet 2006, 368:843-54.

40. Budach W, Her T, Budach V, Belka C, Dietz K: A meta-analysis of hyperfractionated and accelerated radiotherapy and combined chemotherapy and radiotherapy regimens in unresected locally advanced squamous cell carcinoma of the head and neck. BMC Cancer 2006, 6:28.

41. Pignon JP, Bourhis J, Domenge C, Designe L: Chemotherapy added to locoregional treatment for head and neck squamous-cell carcinoma: three meta analyses of updated individual data. MACH-NC Collaborative Group. Meta-analysis of chemotherapy on head and neck cancer. Lancet 2000, 355:949-955.

42. Pignon J-P, le Maitre A, Maillard E, Bourhis J: Meta-analysis of chemotherapy in head and neck cancer (MACH-NC): An update on 93 randomized trials and 17,346 patients. Radiother Oncol 2009, 92:4-14.
43. Budach V, Stuschke M, Budach W, Baumann M, Geismar D, Grabenbauer G, Lammert I, Jahnke K, Stueben G, Herrmann T, Bamberg M, Wust P, Hinkelbein W, Wernecke K-D: Hyperfractionated accelerated chemoradiation with concurrent fluorouracil-mitomycin is more effective than dose-escalated hyperfractionated accelerated radiation therapy alone in locally advanced head and neck cancer: final results of the Radiotherapy Cooperative Clinical Trials Group of the German Cancer Society 95-06 prospective randomized trial. J Clin Oncol 2005, 23:1125-1135

44. Jeremic B, Milicic B, Dagovic A, Vaskovic Z, Tadic L: Radiation therapy with or without concurrent low-dose daily chemotherapy in locally advanced, nonmetastatic squamous cell carcinoma of the head and neck. J Clin Oncol 2004, 22:3540-3548.

45. Huguenin P, Beer KT, Allal A, Rufibach K, Friedli C, Davis JB, Pestalozzi B, Schmid S, Thöni A, Ozsahin M, Bernier J, Töpfer M, Kann R, Meier UR, Thum P, Sabine Bieri, Notter M, Lombriser N, Glanzmann C: Concomitant cisplatin significantly improves locoregional control in advanced head and neck cancers treated with hyperfractionated radiotherapy. J Clin Oncol 2004, 22:4665-4673.

46. Bonner JA, Harari PM, Giralt J, Azarnia N, Shin DM, Cohen RB, Jones CU, Sur R, Raben D, Jassem J, Ove R, Kies MS, Baselga J, Youssoufian H, Amellal N, Rowinsky EK, Ang KK: Radiotherapy plus cetuximab for squamous-cell carcinoma of the head and neck. NEng/ J Med 2006, 354:567-578.

47. Bonner JA, Harari PM, Giralt J, Cohen RB, Jones CU, Sur RK, Raben D, Baselga J, Spencer SA, Zhu J, Youssoufian H, Rowinsky EK, Ang KK: Radiotherapy plus cetuximab for locoregionally advanced head and neck cancer: 5-year survival data from a phase 3 randomised trial, and relation between cetuximab-induced rash and survival. Lancet Oncol 2010, 11:21-28.

48. Haddad Rl, Shin DM: Recent advances in head and neck cancer. NEnglJ Med 2008, 359:1143-1154

doi: 10.1186/1748-717X-5-39

Cite this article as: Krstevska et al., Concurrent radiochemotherapy in advanced hypopharyngeal cancer Radiation Oncology 2010, 5:39

\section{Submit your next manuscript to BioMed Centra and take full advantage of:}

- Convenient online submission

- Thorough peer review

- No space constraints or color figure charges

- Immediate publication on acceptance

- Inclusion in PubMed, CAS, Scopus and Google Scholar

- Research which is freely available for redistribution 